\title{
ON THE APPEARANCE IN THE MARROW OF IRON ADMINISTERED INTRAVENOUSLY
}

\author{
BY \\ H. E. HUTCHISON, C. P. LOWTHER, AND W. D. ALEXANDER \\ From the Department of Pathology, University and Western Infirmary, and the Department of Medicine, \\ Western Infirmary, Glasgow
}

(RECEIVED FOR PUBLICATION MARCH 17, 1954)

Intravenous administration of saccharated oxide of iron is now frequently used in the treatment of hypochromic anaemia where either iron given by mouth is resisted (Hawkins, Peeney, and Cooke, 1950) or rapid improvement is especially important, as in pregnancy (Govan and Scott, 1949), or before surgical operation (Briscoe, 1952). It is therefore surprising that no observations have yet been published regarding the subsequent distribution of the iron in the human body in such cases. It is the purpose of this paper to give a brief description of some observations we have made on the appearance of histologically demonstrable iron in the sternal marrow at different intervals after the intravenous administration of varying amounts of saccharated oxide of iron to patients with iron-deficiency anaemia.

\section{Material and Methods}

On occasion over the past few years the cpportunity has presented itself of examining the marrow of patients undergoing intravenous iron therapy.

It would serve no useful purpose to give details of the haematological and general medical findings in these patients; instead the initial haemoglobin level and a brief clinical diagnosis are listed in each case (Tables I and II). In all cases the response to iron subsequently confirmed the diagnosis of iron deficiency.

When the decision to give intravenous iron was made sternal puncture was carried out in the usual way and the marrow fragments concentrated, sectioned, and stained for iron (Cappell, Hutchison, and Smith, 1947 ; Hutchison, 1953). In accordance with the findings of Davidson and Jennison (1952) and Hutchison (1953) in iron-deficiency anaemia, no stainab!e iron was detected in these initial aspirates. This not only provided immediate confirmation of the diagnosis but prevented the administration of iron when it was not required and so eliminated the possibility of therapeutic siderosis, a material consideration when using parenteral iron (Dameshek, 1950 ; Holly, 1951).

The injections were begun as soon as the initial marrow sample had been examined. The iron preparation used was "ferrivenin" and the initial dose for the patients listed in Table I was $50 \mathrm{mg}$. followed by $100 \mathrm{mg}$., usually on successive days. In the first two cases the second marrow sample was not secured until 24 hours after administration of the total dose necessary to correct the anaemia. In the remaining 11 patients shown in Table I the second marrow sample was secured earlier, when progressively smaller amounts had been given of the total dose of iron judged necessary to meet the patient's haemoglobin deficit, but

TABLE I

CLINICAL FINDINGS

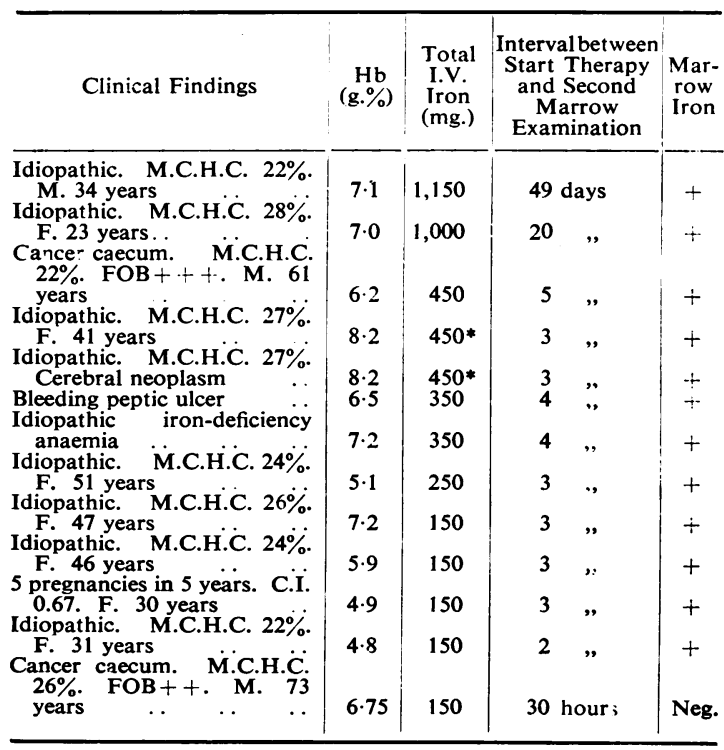

* These patients each received two injections each of $200 \mathrm{mg}$. 
TABLE II

CLINICAL FINDINGS IN SECOND GROUP OF CASES

\begin{tabular}{|c|c|c|c|}
\hline Clinical Findings & $\underset{(\text { g. } \%)}{\mathbf{H b}}$ & $\begin{array}{l}\text { Interval (hours) } \\
\text { between Start } \\
\text { Therapy and } \\
\text { Second Marrow } \\
\text { Examination }\end{array}$ & $\begin{array}{c}\text { Marrow } \\
\text { Iron }\end{array}$ \\
\hline 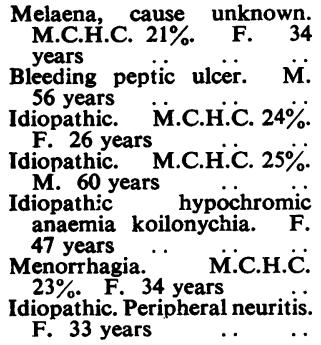 & $\begin{array}{c}9.1 \\
5.9 \\
6.86 \\
8.75 \\
6.2 \\
10.5\end{array}$ & $\begin{array}{l}48 \\
36 \\
24 \\
24\end{array}$ & $\begin{array}{c}+ \\
+ \\
\text { Neg. } \\
+ \text { Trace } \\
+ \\
+ \\
\text { Neg. }\end{array}$ \\
\hline
\end{tabular}

always, unless otherwise stated, 24 hours after the last therapeutic injection.

When it was found that stainable iron could usually be demonstrated in the marrow following as small an amount as $150 \mathrm{mg}$. a second group was studied. These patients were given a single injection of $100 \mathrm{mg}$. and the second marrow sample was collected at varying intervals thereafter as is shown in Table II together with the results of examination for iron. The slight irregularity in the findings is probably due to the technical difficulty of demonstrating small amounts of iron in minute tissue samples.

\section{Comment}

The appearance of stainable iron in previously negative marrows after administration of only a mere fraction of the total dose necessary to correct the anaemia is a significant observation. Saccharated oxide of iron forms colloidal aggregates and has been shown by Cappell (1930) in the mouse to be phagocytosed by the reticulo-endothelial system after intravenous injection.

In the human subject we have found that the iron is deposited in the cells lining the vascular sinusoids (Fig. 1), the distribution that one would expect from a similar, i.e., non-specific, phagocytic mechanism. Furthermore it appears as discrete granules in cells the remainder of whose cytoplasm is negative to the Prussian blue reaction. This particulate form is also suggestive of ingestion and storage of a colloidal preparation presented to the cells in a very low concentration in the blood.

The short interval of 24 hours which elapsed between administration of the 100-mg. dose and the appearance of stainable iron in the marrow is also in keeping with phagocytic activity, for, 24 hours following the injection, the serum iron had returned substantially to the pre-injection level in these patients indicating that the blood had been cleared of the iron put into it.

The particular importance of these findings is that they confirm the supposition based on animal experiments that saccharated oxide of iron given intravenously rapidly becomes deposited in the reticulo-endothelial system. It is clear from the therapeutic responses which the patients subsequently showed that the iron was afterwards utilized. It is not known in what form precisely iron is taken up by developing erythroblasts for incorporation in the haemoglobin molecule, but there is evidence from radio-iron studies both in vivo (Huff, Elmlinger, Garcia, Oda, Cockrell, and Lawrence, 1951) and in tissue culture work that the iron from simple ferric salts conjugated with globulin can very quickly be synthesized into haemoglobin. The rapidity of the therapeutic response to intravenous iron in cases of proved iron deficiency suggests that the transfer from the reticulo-endothelial system to the developing cells takes place extremely rapidly. Our observations suggest that this may possibly be accounted for at least in part by the initial distribution of the iron, some of it having been introduced directly into the sites where it is to be utilized.

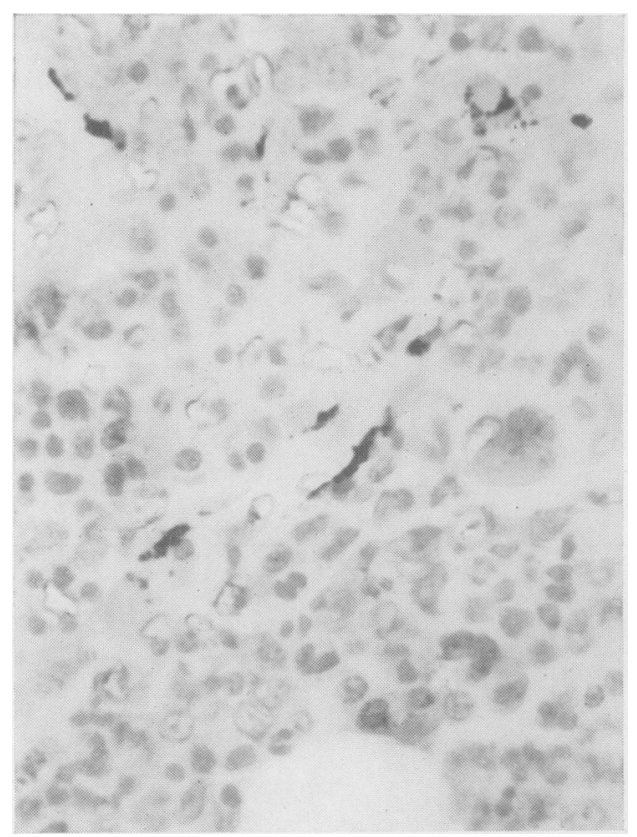

FIG. 1.-Iron granules in sinus-lining cells four days after $350 \mathrm{mg}$. iron intravenously. Prussian blue $\times 680$. 


\section{Summary}

In 20 patients the marrow was examined at different intervals following the administration of varying amounts of iron intravenously for hypochromic anaemia. The appearance and distribution of the stainable iron found are thought to be accounted for by the phagocytic activities of the reticulo-endothelial system.

We would like to thank Dr. J. A. W. McCluskie, physician in charge of wards, for his continued interest in this investigation and Mr. M. Fitch for his careful work in the preparation of the histological sections of the sternal aspirates.

\section{REFFRENCES}

Briscoe C. C. (1952). Amer. J. Obstet. Gynec., 63, 99.

Cappell, D. F. (1930). J. Path. Bact., 33, 175

- Hutchison, H. E., and Smith, G. H. (1947). Brit. med. J., 1, 403. Dameshek, W. (1950). Blood, 5, 1167.

Davidson, W. M., and Jennison, R. F. (1952). Journal of Clinical Pathology, 5, 281.

Govan, A. D. T., and Scott, J. M. (1949). Lancet, 1, 14.

Hawkins, C. F., Peeney, A. L. P., and Cooke, W. T. (1950). Ibid., 2, 387.

Holly, R. G. (1951). Blood, 6, 1159.

Huff, R. L., Elmlinger, P. J., Garcia, J. F., Oda, J. M., Cockrell, M. C., and Lawrence, J. H. (1951). J. clin. Invest., 30, 1512.

Hutchison, H. E. (1953). Blood, 8, 236. 